\title{
Lipid peroxidation and electrogenic ion transport in the jejunum of the vitamin $\mathrm{E}$ deficient rat
}

\author{
K J Lindley, M A Goss-Sampson, D P R Muller, P J Milla
}

\begin{abstract}
Increased concentrations of reactive oxygen species in children with depleted antioxidant defences have been implicated in a cycle of malnutrition, malabsorption, and infection leading to protracted diarrhoea. A rat model of chronic vitamin E deficiency has been used to study the effects of antioxidant depletion on jejunal structure and function in vitro. Basal intestinal short circuit current (Isc), a measure of net electrogenic ion movement across the intestinal eqithelium, was greater in chronically vitamin $\mathbf{E}$ deficient jejuna than controls, as was the electrogenic secretory response to aminophylline and Escherichia coli STa but not to bethanecol. The galactose stimulated current was also greater in vitamin $E$ deficient jejuna. Indices of lipid peroxidation (concentrations of thiobarbituric acid reactive substances and malondialdehyde) were increased in the vitamin E deficient small bowel. Small intestinal brush border membranes from vitamin $\mathbf{E}$ deficient animals displayed changes in both static and dynamic components of membrane fluidity measured by steady state fluorescence polarography. The results of these studies support the hypothesis that oxidative stress in subjects with compromised antioxidant defences results in small intestinal hypersecretion, which could predispose to or perpetuate protracted diarrhoea.

(Gut 1994; 35: 34-39)
\end{abstract}

Protracted diarrhoeal disease is an important cause of morbidity and mortality in young children worldwide. While this represents an enormous problem in the Third World, idiopathic protracted diarrhoea may account for a significant portion of paediatric gastroenterologists workload. ${ }^{1}$ Despite the magnitude of this health problem, little is known about many features of its pathogenesis. Larcher et al have implicated a vicious cycle of infection, malabsorption, and malnutrition in the pathogenesis of protracted diarrhoea, yet the mechanism(s) whereby an apparently minor episode of enteric infection progresses to a potentially life threatening protracted diarrhoeal disease is often unclear. Studies of malnourished infants and children in the West Indies ${ }^{2}$ have reported a decrease in blood concentrations of vitamins A and $E$, and of a number of micronutrients all of which have important roles in limiting cell damage after an oxidising stimulus. Infection, a common precipitant of protracted diarrhoeal disease, can produce a potent oxidising stimulus which, in the presence of impaired antioxidant defences, would be more likely to damage the lipid and proteins of cell membranes. This damage might be expected to have an effect upon the functions of receptors, enzymes, and transporter proteins within that membrane. Vitamin $\mathrm{E}$ is the most important chain breaking antioxidant in biological membranes, ${ }^{3}$ which is present in the small intestine in amounts comparable with those found in many other tissues. ${ }^{4}$ A deficiency of vitamin $\mathrm{E}$ may therefore render the enterocyte membrane more susceptible to oxidative damage. We have examined the hypothesis that vitamin $\mathrm{E}$ deficiency results in oxidative damage to enterocytes leading to a change in gastrointestinal function. Cell damage sustained in this manner might therefore be important in the pathogenesis of protracted diarrhoeal disease. In this paper we report the effects of chronic vitamin E deficiency in a well validated rat model ${ }^{5}$ upon parameters of lipid peroxidation, membrane biophysical characteristics, and intestinal transport in vitro in rat jejunum.

\section{Materials and methods}

MATERIALS

Most chemicals were purchased from Sigma Chemical Company Ltd, Poole, England. 1,6diphenyl-1,3,5-hexatriene (DPH) was obtained from Aldrich Chemical Co (Gillingham, UK) and DL-12-(9-anthroyloxy)-stearic acid (12-AS) from Molecular Probes Inc (Junction City, Oregon, USA).

\section{ANIMALS AND DIET}

Two groups of 21 day old weanling male Wistar rats (Charles Rivers) were placed on synthetic diets (Dyets Inc, Bethlehem, Pennsylvania, USA), based on tocopheryl stripped lard (10\%), vitamin free casein $(20 \%)$, and glucose $(65 \%)$ with a vitamin $\mathrm{E}$ free mineral and vitamin mix (Machlin/Draper-HLR No 814). In one group (vitamin $\mathrm{E}$ sufficient $\left(\mathrm{E}^{+}\right)$) the diet was supplemented with $\alpha$-tocopheryl acetate $(40 \mathrm{mg} / \mathrm{kg}$ of feed). All animals were permitted continued free access to food and water. Animals were housed four to a cage in a room maintained at a temperature of $70^{\circ} \mathrm{C}$ and humidity of $70 \%$ on a 12 hour light/dark cycle. Balance studies were carried out in six animals from both groups (studied individually in metabolic cages) over a five day period in the week before the in vitro transport study.

\section{ELECTROGENIC SECRETION AND ABSORPTION IN} VITRO

Electrogenic secretion and absorption in vitro was studied after 52 weeks on the respective diet. 
After an 18 hour fast, during which time free access to water was permitted, animals were anaesthetised with intraperitoneal sodium pentobarbitone (Sagatal, $60 \mathrm{mg} / \mathrm{kg}$ bodyweight). A $3 \mathrm{~cm}$ segment of jejunum, beginning $15 \mathrm{~cm}$ distal to the ligament of Treitz was removed by a midline incision, irrigated with ice cold Ringer bicarbonate solution (containing ( $\mathrm{mmol} \mathrm{l}^{-1}$ ) $\mathrm{NaCl} 107, \mathrm{KCl} 4 \cdot 5, \mathrm{NaHCO}_{3} 25, \mathrm{Na}_{2} \mathrm{HPO}_{4} 0 \cdot 2$, $\mathrm{NaHG}_{2} \mathrm{PO}_{4} \mathbf{0} \cdot 2, \mathrm{CaCl}_{2} 1 \cdot 25, \mathrm{MgSO}_{4} 1 \cdot 0, \mathrm{pH}$ $7 \cdot 4$, preoxygenated with $95 \% \mathrm{O}_{2} / 5 \% \mathrm{CO}_{2}$ ), and was transported in this same cold sugar free solution before mounting in a modified Ussing chamber. This segment of jejunum was opened along its mesenteric border and mounted unstripped across a number of pins between perspex half chambers, exposing an area of $2 \mathrm{~cm}^{2}$. The maximum time between removal from the animal and mounting in the Ussing chamber was 10 minutes. Each side was bathed with $15 \mathrm{ml}$ of the Ringer bicarbonate solution at $37^{\circ} \mathrm{C}$ oxygenated by a gas lift system with $5 \%$

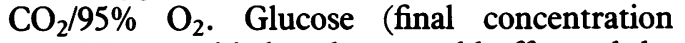
$10 \mathrm{mM}$ ) was added to the serosal buffer and the same amount of mannitol to the mucosal buffer after mounting the tissues. Transepithelial potential difference was measured with calomel electrodes in saturated $\mathrm{KCl}$ by agar salt bridges (3\% agar wt/vol in saturated $\mathrm{KCl}$ washed in Ringer solution), the tips of which were positioned near the tissue surface. Tissues were continuously short circuited at $0 \mathrm{mV}$ with an automatic voltage clamp (World Precision Instruments, New Hampshire, USA) by $\mathrm{Ag} / \mathrm{AgCl}$ electrodes connected to the bathing solutions with salt agar bridges. An adjustable offset with the clamp circuit compensated automatically for the fluid resistance between the tissue and the tips of the potential sensing electrodes. Tissues were unclamped every three minutes to allow measurement of open circuit potential difference and calculation of tissue resistance (Rt) using Ohm's law. A single dose of secretagogue, or mucosal galactose coupled with the simultaneous addition of an equal amount of serosal mannitol, was added 15 minutes after mounting when basal short circuit current (Isc) had reached a stable plateau. No tissue was exposed to more than one of these agents.

The adjacent (aboral) $20 \mathrm{~cm}$ of small bowel was flushed with ice cold Ringer solution, opened along its mesenteric border, and mucosal scrapings were made with a microscope slide. These were snap frozen for biochemical analyses.

\section{BRUSH BORDER MEMBRANES}

Brush border membranes were prepared by $\mathrm{MgCl}_{2}$ precipitation and differential centrifugation and purified on a Percoll density gradient as described by Yakymyshyn et al. ${ }^{6}$ Enrichment of mucosal disaccharidases and alkaline phosphatase was checked by the methods of Dalquhist $^{7}$ and Wilkinson. ${ }^{8}$

\section{PROTEIN AND LIPID ASSAYS}

Protein was measured with a commercial kit using bicinchoninic acid (Pierce, Illinois). The total lipid content of mucosal scrapings was measured by the hydroxamic acid method. ${ }^{9}$

\section{VITAMIN E}

Vitamin $\mathrm{E}$ was measured by high performance liquid chromatography (HPLC) by a modification of the procedure described by Metcalfe et $a l^{10}$ as described previously. ${ }^{5}$

\section{LIPID PEROXIDATION}

Lipid peroxidation was estimated in mucosal scrapings by two methods.

Thiobarbituric acid reactive substances - these were measured according to the method of Yagi. ${ }^{11}$ The resulting fluorescence was measured in a Perkin Elmer LS-3 fluorimeter (Ex $515 \mathrm{~nm}$, Em $553 \mathrm{~nm}$ ) with appropriate blanks and assessed against a standard calibration curve of malondialdehyde $(0-2 \mathrm{mmol} / \mathrm{l})$ prepared by acid hydrolysis of tetramethoxypropane.

Free and total malondialdehyde - free malondialdehyde was measured as the 2,4-dinitrophenylhydrazine (DNPH) derivative by a modification of the methods of Ekstrom ${ }^{12}$ and Kawai. ${ }^{13}$ In summary $100 \mu \mathrm{l}$ of a $25 \%$ (wt/vol) homogenate of mucosal scrapings in $0.1 \mathrm{M}$ phosphate buffer $\mathrm{pH} 7 \cdot 4$ was mixed thoroughly with an equal volume of acetonitrile, spun at $16000 \mathrm{rpm}$ in an Eppendorf centrifuge for two minutes, and $125 \mu \mathrm{l}$ of the supernatant decanted. To this was added $12.5 \mu \mathrm{l} 2 \mathrm{M} \mathrm{HCl}$, $5 \mu \mathrm{l} \mathrm{DNPH}(0.5 \mathrm{mg} / \mathrm{ml}$ in $1 \mathrm{M} \mathrm{HCl})$ and $5 \mu \mathrm{l}$ $62.5 \mathrm{nM}$ nitroresorcinol (internal standard). The mixture was allowed to stand at room temperature for 60 minutes and a $20 \mu \mathrm{l}$ aliquot analysed by HPLC. HPLC conditions were mobile phase $45 \%$ acetonitrile $/ 55 \% 0 \cdot 1 \mathrm{M} \mathrm{HCl}$, flow rate $1 \mathrm{ml} /$ $\mathrm{min}$, column Spherisorb 5-0DS2 $(250 \times 4.6 \mathrm{~mm}$ ID) reverse phase (Pharmacia) maintained at room temperature and fitted with a Spherisorb 5-ODS guard column. Malondialdehyde peaks were detected by ultraviolet absorption at 310 $\mathrm{nm}$ and the peak areas compared with malondialdehyde standard after correcting for the amount of internal standard. Total malondialdehyde was measured after subjecting the sample to alkaline hydrolysis in $0 \cdot 1 \%$ sodium hydroxide at about $60^{\circ} \mathrm{C}$ for 30 minutes in the presence of $0.05 \%(\mathrm{wt} / \mathrm{vol})$ promethazine as an antioxidant. In validating this method of measuring malondialdehyde we found it to have an intrabatch coefficient of variation of $3 \cdot 3 \%$. Recoveries of malondialdehyde were about $96 \cdot 5 \%$.

TOTAL FATTY ACID ANALYSIS

A chloroform/methanol (2:1) lipid extract of brush border membranes was made according to the method of Folch ${ }^{14}$ after the addition of nonadecanoic acid internal standard. This total lipid extract was dried down under nitrogen, taken up into dry $3 \mathrm{M}$ methanolic $\mathrm{HCl}$ (Superlco) for saponification at $65^{\circ} \mathrm{C}$ for four hours, and later extracted into hexane for analysis by gas chromatography. Gas chromatography-mass spectrometry was performed on a Hewlett Packard 5890 gas chromatograph coupled to a 5970 series mass selective detector. The fatty 
acid methyl esters were separated on a fused silica capillary column $(30 \mathrm{~m} \times 0.25 \mathrm{~mm}$ inside diameter) with a $0.25 \mu \mathrm{m}$ chemically bonded BDI stationary phase ( $\mathrm{J}$ and $\mathrm{W}$ Scientific, Falsom, CA95630 USA). The initial column temperature was $50^{\circ} \mathrm{C}$ rising at $50^{\circ} \mathrm{C} / \mathrm{min}$ to $190^{\circ} \mathrm{C}, 2 \cdot 5^{\circ} \mathrm{C} / \mathrm{min}$ to $213^{\circ} \mathrm{C}, 5^{\circ} \mathrm{C} / \mathrm{min}$ to $260^{\circ} \mathrm{C}$, and $60^{\circ} \mathrm{C} / \mathrm{min}$ to $300^{\circ} \mathrm{C}$. Aliquots of $1 \mu$ l were injected in splitless mode with an injector temperature of $250^{\circ} \mathrm{C}$. The detector temperature was $300^{\circ} \mathrm{C}$. Fatty acids were identified by their retention time and by comparison of their total ion chromatogram with that of known standards. Quantitative measurement was achieved by peak area integration with reference to a known concentration of standards. The coefficients of variation for this method varied from $1.5 \%$ for the saturated and monounsaturated fatty acids to about $8 \%$ for arachidonic acid and docosahexaenoic acid. These are comparable with those found in published works. ${ }^{15}$

\section{FLUORESCENCE ANISOTROPY}

Steady state fluorescence polarisation studies were performed using a Perkin Elmer LS-3 fluorescence spectrophotometer according to standard methodology. ${ }^{16}$ Two hundred $\mu$ l of brush border membrane suspension (about 200 $\mu \mathrm{g}$ of protein) was incubated for 30 minutes at $30^{\circ} \mathrm{C}$ with $1 \mathrm{ml}$ of $5 \mu \mathrm{M} \mathrm{DPH}$ or $12-\mathrm{AS}$ in hydroxyethylpiperazine-ethanesulphonic acid (HEPES) buffer. At the end of this period the brush border membrane was pelleted and resuspended in fresh HEPES buffer. The content of fluorophore in the preparations was estimated fluorometrically as described by Cogan. ${ }^{17}$ Corrections for light scattering and for fluorescence in the ambient medium were routinely made. Excitation and emission parameters were as follows: for DPH Ex $360 \mathrm{~nm}, \operatorname{Em} 430 \mathrm{~nm}$; for 12-AS Ex 360 nm, Em 471 nm.

Anistropy was calculated from the polarised fluorescence intensities using the standard equation anisotropy, $\mathbf{R}_{\mathrm{s}}=(\mathrm{Iv}-\mathbf{I H}) /(\mathbf{I v}-2 \mathrm{IH}) .{ }^{18}$

\section{HISTOLOGICAL STUDIES}

Small pieces of jejunum, immediately adjacent to that used in the Ussing chamber, were either fixed in $4 \%$ paraformaldehyde in $0.01 \mathrm{M}$ phosphate buffered saline, $2 \cdot 5 \%$ (wt/vol) glutaraldehyde in $0.1 \mathrm{M}$ phosphate buffer, or snap frozen to allow processing for light and electron microscopy.

\section{STATISTICS}

Unless otherwise stated, comparisons were made using Student's unpaired $t$ test. Non-parametric data were analysed using the Kruskal-Wallis one way analysis of variance. Figures in parenthesis after the means or medians are the $95 \%$ confidence intervals for this parameter unless otherwise stated. $n$ Refers to the number of animals in each group.

\section{Results}

Figure 1 shows the longitudinal growth data for the two groups of animals. The weight of the Egroup lagged behind that of the $\mathrm{E}+$ group from 20 weeks after weaning onto the diets. After 52 weeks the $\mathrm{E}-$ animals were significantly lighter than $\mathrm{E}+(\mathrm{E}+$ mean $733 \mathrm{~g} \mathrm{(40)}, \mathrm{E}-519 \mathrm{~g}$ (44), $\mathrm{n}=40 \mathrm{p}<0.01)$. Animals on vitamin $\mathrm{E}$ free $(\mathrm{E}-)$ diets developed signs of a hind limb ataxia after about six months on the diet, as previously described. ${ }^{5}$ An important element in the difference in weight between groups resulted from muscle wasting - a characteristic of the neurological syndrome accompanying chronic vitamin $\mathrm{E}$ deficiency in this rat model. ${ }^{5}$

E- rats ate significantly less diet than E+ when balances were performed in the week before the in vitro transport studies $(E+23.5$ $\mathrm{g} / \mathrm{kg}^{-1} 24 \mathrm{~h}^{-1}(1.8) v \mathrm{E}-21.5 \mathrm{~g} / \mathrm{kg}^{-1} 24 \mathrm{~h}^{-1}$ $(1 \cdot 2), \mathrm{n}=12, \mathrm{p}<0.05)$. Neither group of animals developed diarrhoea, and stool output (g/24 h) was the same in both groups.

Plasma vitamin $\mathrm{E}$ concentrations declined rapidly after weaning in the $\mathrm{E}-$ group and rose to a stable plateau in the $\mathrm{E}+$ group (Fig 2). Sixteen weeks after starting the diets the mean plasma concentration was $34.5(1.4) \mu \mathrm{mol} / 1$ in $\mathrm{E}+$ animals, but undetectable in the $\mathrm{E}-$.

After 52 weeks on the diet, vitamin $\mathrm{E}$ was undetectable in mucosal scrapings from $\mathrm{E}$ jejuna, but abundant in $\mathrm{E}+$ jejuna (mean 1.33 $(0.09) \mu \mathrm{mol} / \mathrm{g}$ lipid, $\mathrm{n}=6)$.

Basal short circuit current was significantly higher $(\mathrm{p}<0.005)$ in the $\mathrm{E}$ - group than the $\mathrm{E}+$ group (Table I). This is reflected in the higher transepithelial potential difference. Tissue resistances were comparable. Substitution of the bathing solutions with a chloride free medium on both the mucosal and serosal sides (gluconate replacing $\mathrm{Cl}$ ) led to a reversible $75-80 \%$ decrement in basal Isc in both groups. Application of $1.25 \mu \mathrm{M}$ tetrodotoxin to the serosal surface of unstimulated tissues had no effect on Isc in either group. Table II shows the effect of added secretagogues. Ten mM mucosal and serosal aminophylline produced a greater increment in Isc in the $\mathrm{E}$ - animals as did mucosal $E$ coli heat stable toxin (STa) at a concentration of 60 mouse units $\mathrm{ml}^{-1}$. The increment in Isc seen with $1 \mathrm{mM}$ serosal bethanecol was comparable in $\mathrm{E}+$ and E- jejuna.

The maximal $\Delta$ Isc produced by the addition of $28 \mathrm{mM}$ galactose to the mucosal surface was significantly higher in the $\mathrm{E}-$ group $(114 \mu \mathrm{A}$ $\left.\mathrm{cm}^{-2}(29) v 75 \mu \mathrm{A} \mathrm{cm}{ }^{-2}(18), \mathrm{n}=8, \mathrm{p}<0.05\right)$ as 
Figure 2: Longitudinal plasma vitamin $E$ concentrations of rats fed vitamin $E$ sufficient $(O)$ and vitamin $E$ deficient $(\boldsymbol{\Delta})$ diets. Error bars $=95 \%$ confidence intervals for the mean; $n=12$ in each group.
Figure 3: $\Delta$ Isc produced by addition of mucosal galactose to unstripped jejuna from 12 month vitamin $E$ sufficient $(O)$ and deficient ( $\mathbf{\Delta})$ rats. Error bars are $95 \%$ confidence intervals for the mean. ${ }^{\star} p<0.05$, ${ }_{\star \star} p<0 \cdot 01$, Student's $\mathrm{t}$ test $n=12-14$ animals in each group.

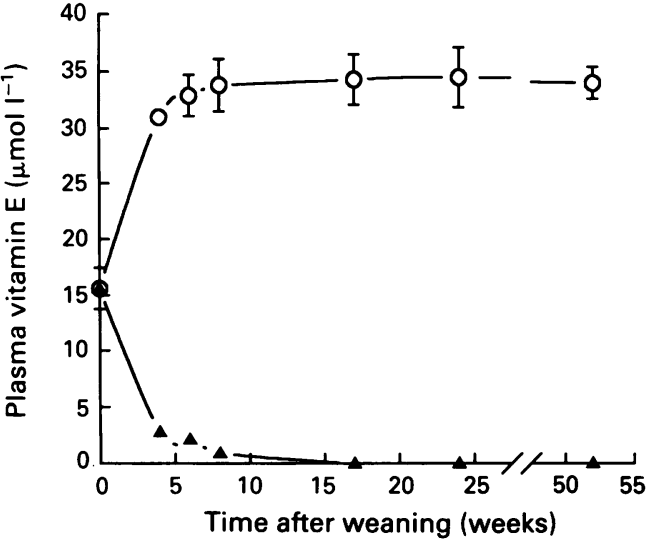

TABLE I Basal electrical characteristics of unstripped jejunum from 12 month old vitamin $E$ sufficient (control) and deficient rats shown as mean ( $\pm 95 \%$ confidence intervals for mean)

\begin{tabular}{llll}
\hline & $\begin{array}{l}\text { Control } \\
(n=40)\end{array}$ & $\begin{array}{l}\text { Deficient } \\
(n=40)\end{array}$ & \\
\hline Basal Inc $\mu \mathrm{A} \mathrm{cm}^{-2}$ & $73(11)$ & $91(10)$ & $\mathrm{p}<0.005$ \\
Tissue resistance $\Omega \mathrm{cm}^{2}$ & $77(11)$ & $72(6)$ & $\mathrm{NS}$ \\
Basal pd mV & $5.62(0.46)$ & $6.55(0.75)$ & $\mathrm{p}<0.05$ \\
\hline
\end{tabular}

Isc $=$ intestinal short circuit current $; \mathrm{pd}=$ potential difference .

TABLE II Increment in short circuit current $\left(\mu A \mathrm{~cm}^{-2}\right)$ produced by secretagogues in unstripped jejunum from 12 month vitamin $E$ sufficient (control) and deficient rats

\begin{tabular}{llll}
\hline & Control & Deficient & \\
\hline $\begin{array}{l}1 \mathrm{mM} \text { bethanecol } \\
\text { (serosa) }\end{array}$ & $32(9)$ & $34(9)$ & $\begin{array}{l}(\mathrm{n}=12) \\
\mathrm{NS}\end{array}$ \\
$\begin{array}{l}10 \mathrm{mM} \text { mucosal and } \\
\text { serosal aminophylline }\end{array}$ & $34(9)$ & $56(15)$ & $\begin{array}{l}(\mathrm{n}=14) \\
\mathrm{p}<0.05 \star\end{array}$ \\
$\begin{array}{l}E \text { coli STa 60 mouse } \\
\text { U/ml }\end{array}$ & $15(5$ to 55) & $32(25$ to 98) & $\begin{array}{l}\mathrm{n}=10) \\
\mathrm{p}<0.05 \dagger\end{array}$ \\
\hline
\end{tabular}

${ }^{\star}$ Mean ( $\pm 95 \%$ confidence intervals for mean), Student's $t$ test; tmedian ( $95 \%$ confidence intervals for median), Kruskal-Wallis one way analysis of variance; $E$ coli $\mathrm{STa}=E$ scherichia coli heat stable toxin
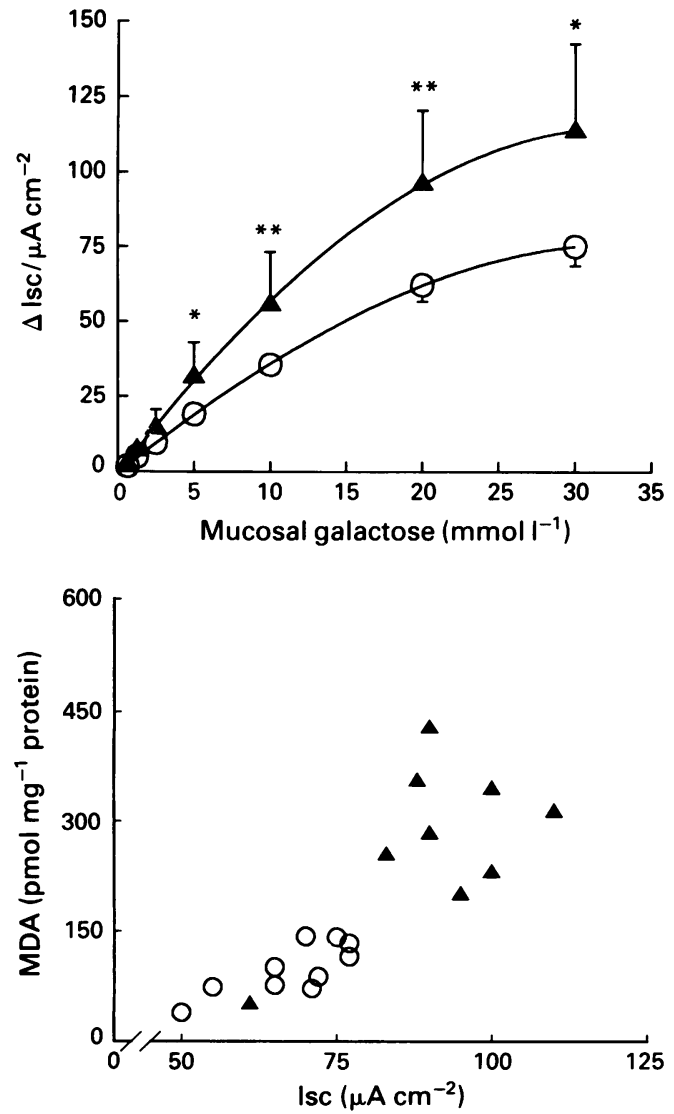

were the maximal responses to 5,10 , and $20 \mathrm{mM}$ galactose (Fig 3).

Mucosal thiobarbituric acid reactive substances were significantly greater in the $\mathrm{E}$ animals $(\mathrm{E}+0.67(0.09) v \mathrm{E}-0.83(0.09) \mathrm{nmol} /$ mg protein, $n=10, p<0.05)$.

Concentrations of both free and total malondialdehyde were significantly higher in the $\mathrm{E}$ jejuna. (Free malondialdehyde E+ 100 (20) pmol $\mathrm{mg}^{-1}$ protein $v \mathrm{E}-307(96) \mathrm{pmol} \mathrm{mg}^{-1}$ protein, $\mathrm{n}=11, \mathrm{p}<0.01$; total malondialdehyde $\mathrm{E}+168(30) \mathrm{nmol} / \mathrm{mg}$ protein $v \mathrm{E}-397(109)$, $p<0 \cdot 05, n=6$.) Higher concentrations of malondialdehyde seemed to be associated with higher short circuit currents (Fig 4). It would be unreasonable to expect a simple linear relation between Isc and malondialdehyde and hence regression data are not provided.

Steady state anisotropies with both probes in proximal intestinal brush border membranes with higher in E- animals. (DPH E+ 0.209 $(0.008-99 \% \mathrm{CI}) v \mathrm{E}-0.231(0.005), \mathrm{n}=6$, $\mathrm{p}<0.01 ; 12$-AS E+ $0.0902\left(4.6 \times 10^{-3} 99 \% \mathrm{CI}\right) v$ E- $\left.0.0967\left(6.2 \times 10^{-3}\right), n=6, p<0.01\right)$.

The total fatty acid composition of the two groups of brush border membrane (expressed as mol \%) showed no statistically significant differences in fatty acid profile (Table III). The ratio of total lipid to protein in the brush border membrane $(\mu \mathrm{mol} / \mathrm{mg})$ was, however, significantly higher in the controls $(\mathrm{E}+0.62(0.03), \mathrm{E}-0.54$ $(0.04), \mathrm{n}=12, \mathrm{p}<0.05)$, and so the absolute amount of each fatty acid present was less in the E- brush border membrane.

Histological studies of sections cut from jejuna of both groups showed no significant differences with either light or electron transmission microscopy (Fig 5).

\section{Discussion}

Protracted diarrhoeal disease remains an important world health problem accounting for roughly five million deaths worldwide each year. The pathogenesis of the progression from a seemingly minor infective diarrhoeal episode to this life threatening disorder remains ill understood. The intimate association of protracted diarrhoeal disease with malnutrition and malabsorption ${ }^{1}$ and the compelling arguments of Golden $e t a l^{2}$ led us to explore the relation between vitamin $\mathrm{E}$ deficiency, free radical production, and small intestinal secretion and absorption.

This study shows an increase in both basal and

TABLE III Fatty acid composition (total lipids) of brush border membranes from proximal small intestines of 12 month vitamin $E$ sufficient (control) and deficient rats

\begin{tabular}{|c|c|c|}
\hline & Control & Deficient \\
\hline $14: 0$ & $1.17(0.51)$ & $0.91(0.33)$ \\
\hline $16: 1$ & $1.39(0.56)$ & $1.11(0.51)$ \\
\hline $16: 0$ & $26.66(2.35)$ & $26.59(1.85)$ \\
\hline $18: 2$ & $6.23(1.45)$ & $5.27(0.64)$ \\
\hline $18: 1$ & $13 \cdot 78(2 \cdot 15)$ & $14 \cdot 19(1 \cdot 70)$ \\
\hline $18: 0$ & $24 \cdot 19(3 \cdot 10)$ & $23.83(2.55)$ \\
\hline $20: 4$ & $23.58(4.00)$ & $25 \cdot 74(3 \cdot 70)$ \\
\hline $20: 0$ & $0.82(0.17)$ & $0.58(0.31)$ \\
\hline $22: 6$ & $0.87(0.29)$ & $1.01(0.33)$ \\
\hline $22: 4$ & $0.56(0.16)$ & $0.69(0.28)$ \\
\hline 22:0 & $0.72(0.09)$ & $0.59(0.32)$ \\
\hline
\end{tabular}

Data shown as mol \% composition of total fatty acids (mean ( $\pm 95 \%$ confidence intervals for mean)); $n=6$ in each group. 

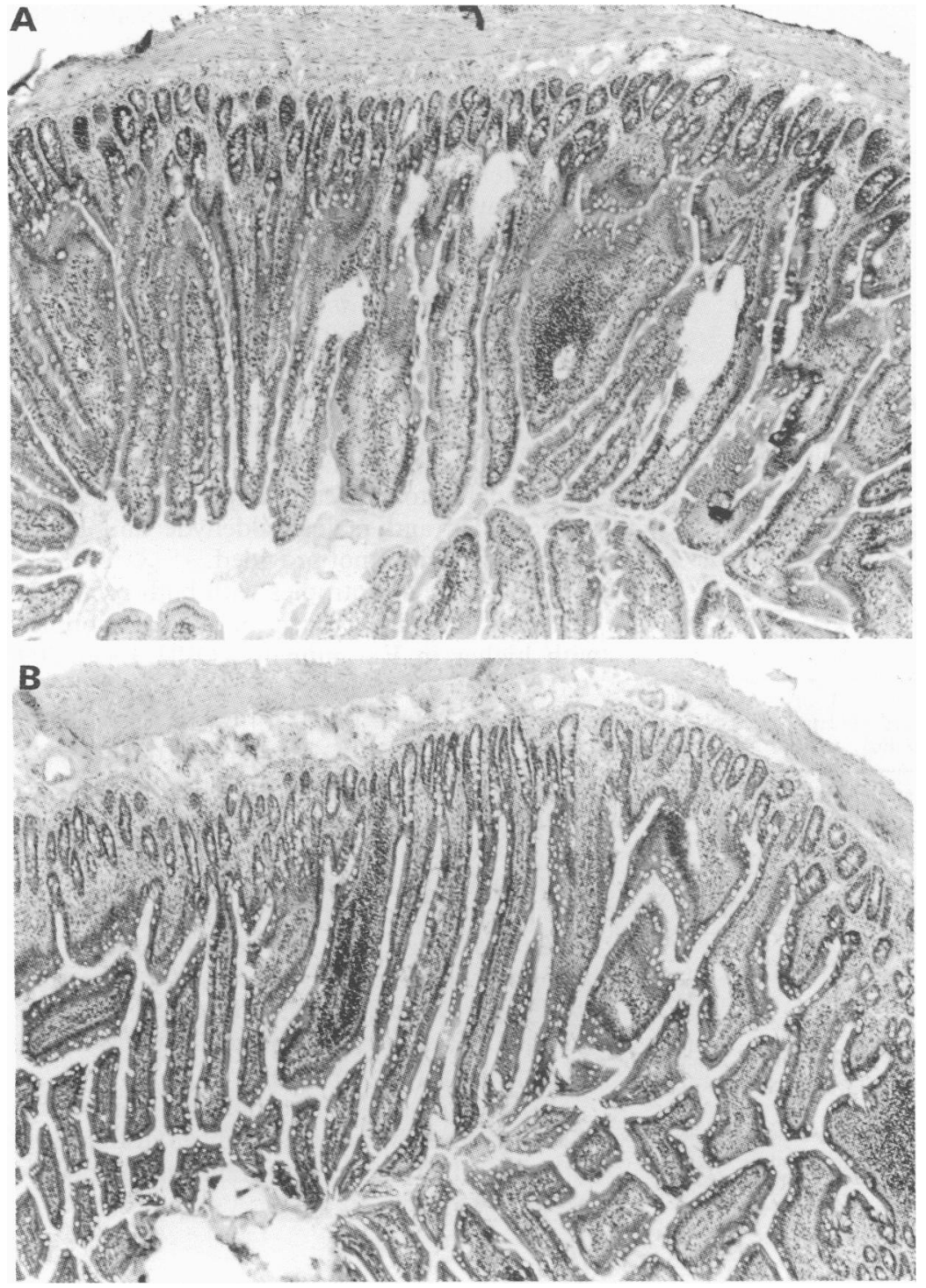

Figure 5: Light microscopic appearance of histological sections of jejunum.

Haematoxylin and eosin stain, $\times 16$ magnification. (A) Vitamin E sufficient; (B) vitamin $E$ deficient. secretagogue induced electrogenic anion secretion and galactose coupled cation absorption in the small intestine in chronic vitamin $E$ deficiency. These findings are associated with increased levels of lipid peroxidation within the small intestinal mucosa and a biophysical change in the enterocyte apical membrane.

We have used vitamin $\mathrm{E}$ deficiency as a means to increase free radical fluxes because this is the most important lipid soluble antioxidant in biological membranes. ${ }^{3}$ Vitamin E, however, has both antioxidant and structural roles in biological membranes, ${ }^{19}$ and so our model is one of both vitamin $\mathrm{E}$ depletion and increased free radical fluxes. The small intestine has an innate resistance to oxidative damage, ${ }^{20-22}$ which is independent of vitamin $E$, and this may account for the comparatively small changes seen in both lipid peroxidation and electrogenic secretion despite a chronic and severe deficiency of vitamin $E$. Increasing free radical fluxes within the small intestine by other means, for example with ionising radiation, has been shown to result in a decrease in net fluid absorption. ${ }^{23}$ Recently, an increase in electrogenic chloride secretion and a reduction in electroneutral sodium and chloride absorption in colon has been shown after exposure of the serosa to hydrogen peroxide. ${ }^{24}$
These effects were apparently largely because of the actions of released prostaglandins on nerves within the lamina propria, and almost certainly not to oxidative damage to the enterocyte membrane. In contrast, in this study the increase in short circuit current (Isc) seen in vitamin $E$ deficient jejuna could not be abolished by neural blockade with tetrodotoxin. Our findings, therefore, suggest that oxidative damage to the enterocyte in vitamin $\mathrm{E}$ deficiency is associated with small intestinal hypersecretion.

The E- group of animals ate less food than $\mathrm{E}+$, suffering in effect from chronic undernutrition. We did not pair feed the animals. If vitamin $\mathrm{E}$ deficiency induces anorexia or satiety then we felt this appropriate for the purposes of this study. Undernutrition (33\% of normal intake for nine days) has no effect on basal Isc in stripped duodenum, jejunum, or ileum, but is associated with increased electrogenic secretory responses in jejunum to the $\mathrm{Ca}^{2+}$ mobilising agonists bethanecol, ${ }^{25} 5$ hydroxytryptamine, and prostaglandin $\mathrm{E}_{2}{ }^{26}$ and also to $E$ coli STa. ${ }^{27}$ The secretory response to dibutyryl cAMP and forskolin, which cause secretion by cyclic AMP dependent mechanisms was not increased in these studies. These patterns of jejunal hypersecretion are quite different from those found in our vitamin $\mathrm{E}$ deficient 'chronically undernourished' rat.

Chronic vitamin $\mathrm{E}$ deficiency in humans ${ }^{28}$ and in our model ${ }^{29}{ }^{30}$ is associated with a characteristic neuropathy of the peripheral, central, and autonomic nervous systems. The enteric nervous system is important in the control of intestinal ion transport. We were unable to show any histological or histochemical evidence of a neuropathy in E+ or E- jejuna, or any pharmacological evidence of an increase or decrease in neural tone that might have given rise to the noted changes in secretion and absorption.

We used two methods to detect oxidative damage within the intestinal mucosa. The thiobarbituric acid assay is a widely used measure of lipid peroxidation. This test is sensitive though not specific and prone to interference. ${ }^{31} \mathrm{We}$ therefore measured malondialdehyde by high performance liquid chromatography, which is both sensitive and specific. Malondialdehyde is one of a group of cytotoxic aldehydes formed as secondary products of lipid peroxidation after the metal ion dependent decomposition of lipid hydroperoxides. Our findings of increased concentrations of both thiobarbituric acid reactive substances and free malondialdehyde in Ejejuna are consistent with a greater degree of oxidative damage within these jejuna. The association of higher concentrations of mucosal malondialdehyde with higher values for basal Isc may provide indirect evidence that oxidative damage rather than vitamin $\mathrm{E}$ deficiency in itself gives rise to the increased secretion, though this matter requires further clarification.

The changes in membrane biophysical characteristics reported in this study could have arisen by a number of means including a variation in the lipid/protein ratios within the membranes, directly as a consequence of vitamin $E$ deficiency, or as a consequence of peroxidation and crosslinking of membrane lipids ${ }^{32}$ or lipids 
with proteins. Vitamin E depletion alone without lipid peroxidation would, however, be expected to decrease the measured anisotropies with both probes - that is, 'fluidise' the membranes. ${ }^{33} \mathrm{~A}$ decrease in the lipid/protein ratio of the apical membrane, as has been noted to occur in the vitamin $\mathrm{E}$ deficient animals, would have the effect of increasing the measured anisotropy with both the probes used though given the magnitude of the change it is unlikely that this accounts for the increase in anisotropy on its own. The anisotropy data presented here pertain to a membrane 'average', and the use of probes that partition into different membrane lipid domains might provide further understanding of the changes we have seen. The relation between these changes in fluidity and enhanced intestinal secretion is unclear. There are other mechanisms whereby oxidising stress might predispose to secretion including direct actions upon membrane proteins ${ }^{34}$ and release of pro secretory substances from the subepithelium.

This study shows that chronic vitamin $\mathrm{E}$ deficiency is associated with oxidative damage within the small intestinal mucosa, a change in enterocyte apical membrane biophysical characteristics, and enhanced basal and secretagogue induced secretion and sodium coupled glucose absorption. The relation between these findings is worthy of further investigation.

There are clearly many reasons why malnourished children should be prone to develop protracted diarrhoea. ${ }^{35}$ Our data lend support to the hypothesis that malnourished children with depleted antioxidant defences ${ }^{36}$ are predisposed to upper small intestinal hypersecretion. We suggest that this is one mechanism whereby malnutrition might predispose to the perpetuation of the diarrhoeal state. This will have implications not only for subjects with idiopathic protracted diarrhoea but also for malnourished subjects in whom a specific cause for the diarrhoea has been ascertained.

Parts of these data have been presented to the British Society of Gastroenterology, the European Society of Paediatric Gastroenterology and Nutrition, and the Physiological Society, and have entered in their publications in abstract form.

KJL was supported by a Children Nationwide Research $\mathrm{KJL}$ was suppor
Training Fellowship.

1 Larcher VF, Shepherd R, Francis DEM, Harries JT Protracted diarrhoea of infancy: an analysis of 82 cases with particular reference to diagnosis and management. Arch Dis Child 1977; 52: 597-605.

2 Golden MNH, Ramdath D. Free radicals in the pathogenesis of Kwashiorkor. Proc Nutr Soc 1987; 46: 53-68.

3 Burton GW, Joyce A, Ingold K. Is vitamin E the only lipid soluble chain breaking antioxidant in human blood plasma and erythrocyte membranes. Arch Biochem Biophys 1983; 221: 281-90.

4 Manohar M, Balasubramanian KA. Distribution of $\alpha$ tocopherol in the rat gut. Indian f Biochem Biophys 1982; 19: tocoph

5 Goss-Sampson MA, MacEvilly CJ, Muller DPR. Longtidinal studies of the neurobiology of vitamin $E$ and other antoxidant systems, and neurological function in the vitamin $\mathrm{E}$ dant systems, and neurological function in

6 Yakymyt Percoll $^{\mathrm{TM}}$ in the isolation and purification of rabbit small intestinal brush border membranes. Biochim Biophys Acta 1982; 690: 269-81.
7 Dahlquist A. Assay of intestinal disaccharidases. Enzymologia Biologica et Clinica 1970; 11: 52-66.

8 Wilkinson JH, Boutwell JH, Winsten S. Evaluation of a new system for kinetic measurement of alkaline phosphatase. system for kinetic measuremer

9 Snyder F, Stephens N. A simplified spectrophotometric determination of ester groups in lipids. Biochim Biophys Acto 1959; 34: 244-5.

10 Metcalf T, Bowen DM, Muller DPR. Vitamin E concentrations in human brain of patients with Alzheimer's disease, fetuses with Down's syndrome, centenarians and controls. Neurochem Res 1989; 14: 1209-12.

11 Yagi K. A simple fluorometric assay for lipoperoxide in blood plasma. Biochem Med 1976; 15: 212-6.

12 Ekstrom T, Garberg P, Egestad B, Hogberg J. Recovery of malondialdehyde in urine as a 2,4-dinitrophenylhydrazine derivative analysed with high performance liquid chromatoderivative analysed with high performance liqui

13 Kawai S, Kasashima K. High performance liquid chromatographic determination of malondialdehyde in serum. graphic determination of mator

14 Folch J, Lees M, Sloane SGM. A simple method for the isolation and purification of total lipids from animal tissues. f Biol Chem 1957; 226: 497-507.

15 Fosbrooke AS, Tamir I. A modified method for the preparation of methyl esters of a mixture of medium chain and long chain fatty acids. Clin Chim Acta 1968; 20: 517-22.

16 Brasitas TA, Schachter D, Mamouneas TG. Functional interactions of lipids and proteins in rat intestinal microvillous membranes. Biochemistry 1979; 18: 4136-44.

17 Cogan U, Schachter D. Asymmetry of lipid dynamics in human erythrocyte membranes studied with impermeable fluophores. Biochemistry 1981; 20: 6396-403.

18 van Ginkel G. Diphenyl hexatrienes as fluorescent membrane probes. Applied Fluorescence Technology 1989; 1: 1-8.

19 Urano S, Inomori Y, Sugawara T, Kato Y, Kitahara M Hasegawa $Y$, et al. Vitamin $E$ : inhibition of retinol induced haemolysis and membrane stabilising behavior. $\mathcal{F}$ Biol Chem 1992; 267: 18365-70.

20 Balasubramanian KA, Nalini S, Cheeseman KH, Slater TF Nonesterified fatty acids inhibit iron dependent lipid peroxidation. Biochim Biophys Acta 1989; 1003: 232-7.

21 Balasubramanian KA, Manohar M, Mathan VI. An unidentified inhibitor of lipid peroxidation in intestinal mucosa. Biochim Biophys Acta 1988; 962: 51-8.

22 Diplock AT, Balasubramanian KA, Manohar M, Mathan VI, Ashton D. Purification and chemical characterisation of the inhibitor of lipid peroxidation from intestinal mucosa. Biochim Biophys Acta 1988; 962: 42-50.

23 Empey LR, Papp JD, Jewell LD, Fedorak RN. Mucosal protective effects of vitamin $E$ and misoprostol during acute radiation induced enteritis in rats. Dig Dis Sci 1992; 37: 20514.

24 Karayalcin SS, Sturbaum CW, Wachsman JT, Cha J-H, Powell DW. Hydrogen peroxide stimulates rat colonic prostaglandin production and alters electrolyte transport. f Clin Invest 1990; 86: 60-8.

25 Young A, Nzegwu HC, Levin RJ. The effects of restricted food intake on intestinal secretion in the rat small intestine. Proc Nutr Soc 1988; 47: 127A.

26 Pereria MMC, Levin RJ, Young A. The effect of acute undernutrition on rat jejunal and ileal secretion in vitro. Proc Nutr Soc 1989; 48: 78A.

27 Levin RJ, Nzegwu H, Pereira M, Young A. Malnourishment enhances the in vitro electrogenic secretory response to $\mathrm{E}$ coli STa enterotoxin in rat small and large intestine. f Physiol 1988; 406: 56P

28 Muller DPR, Lloyd JK, Wolff OH. Vitamin E and neurological function. Lancet 1983; ii: 225-8.

29 Goss-Sampson MA, Kriss A, Muller DPR. A longitudinal study of somatosensory, brainstem auditory and peripheral sensory-motor conduction during vitamin $\mathrm{E}$ deficiency in sensory-motor conduction during vitam
the rat. $\mathcal{F}$ Neurol Sci 1990; 100: 79-84.

30 Bisset WM, Goss-Sampson MA, Ravelli AM, Milla PJ. The effect of chronic vitamin E deficiency on gastric electrical effect of chronic vitamin E deficiency on gastric electrical
control activity. F Pediatr Gastroenterol Nutr 1992; 15: 353 .

31 Gutteridge JMC, Halliwell B. The measurement and mechanism of lipid peroxidation in biological systems. Trends Biochem Sci 1990; 15: 129-35.

32 Eichenberger K, Bohni P, Winterhalter KH, Kawato S, Richter C. Microsomal lipid peroxidation causes an increase in the order of the membrane lipid domain. FEBS Letters 1982; 142: 59-62.

33 Bisby RH, Birch DJS. A time resolved fluorescence anisotropy study of bilayer membranes containing $\alpha$ tocopherol. Biochem Biophys Res Commun 1989; 158: 386-91.

34 Dean RT, Cheeseman KH. Vitamin E protects protein against free radical damage in lipid environments. Biochem Biophys free radical damage in lipid envir

35 Levin RJ. The diarrhoea of famine and malnutrition - is glucagon the major culprit? Gut 1992; 33: 432-4.

36 Thurnham DI. Antioxidants and prooxidants in malnourished populations. Proc Nutr Soc 1990; 49: 247-59. 